\title{
Unlocked Nailing vs. Interlocking Nailing for Winquist Type I and II Femoral Isthmus Fractures. Is there a Difference?
}

\author{
CK Yu, MBBS (UM), HY Wong*, MD (UKM), AS Vivek, FRCS (Edin), BC Se To*, FRCS (Edin) \\ Department of Orthopaedics, University Malaya Medical Centre, Kuala Lumpur, Malaysia \\ * Department of Orthopaedics, Penang General Hospital, Penang, Malaysia
}

\begin{abstract}
Interlocking intramedullary nailing is suitable for comminuted femoral isthmus fractures, but for noncomminuted fractures its benefit over unlocked nailing is debatable. This study was undertaken to compare outcomes of interlocking nailing versus unlocked intramedullary nailing in such fractures. Ninety-three cases of noncomminuted femoral isthmus fractures (Winquist I and II) treated with interlocking nailing and unlocked nailing from 1 June 2004 to 1 June 2005 were reviewed; radiological and clinical union rates, bony alignment, complication and knee function were investigated. There was no statistical significant difference with regard to union rate, implant failure, infection and fracture alignment in both study groups. Open fixation with unlocked femoral nailing is technically less demanding and requires less operating time; additionally, there is no exposure to radiation and cost of the implant is cheaper. We therefore conclude that unlocked nailing is still useful for the management of non-comminuted isthmus fractures of the femur.
\end{abstract}

Key Words:

Fracture; Femur; Winquist I and II; Küntscher nail; Interlocking nail.

\section{INTRODUCTION}

Intramedullary nailing is the gold standard for the management of femoral shaft fractures ${ }^{1,2,3,4}$. Various studies have shown that it is superior to plate fixation due to lower rates of infection and non-union ${ }^{5,6,7}$. As a load-sharing implant, it allows earlier weight bearing after surgery ${ }^{8}$.

The Küntscher nail (K-nail), one of the earliest intramedullary nails was frequently recommended for fixation of non-comminuted femoral shaft fractures. The advent of interlocking intramedullary nails (ILN) has extended intramedullary nails applicability to a wider variety of femoral fractures. The current trend is towards increasing usage of ILN for all types of femoral shaft fractures, although the benefit for more simple fractures is not well established. We therefore conducted this study to compare the outcome between the use of the K-nail and the ILN for fixation of Winquist type I and II femoral shaft fractures.

\section{MATERIALS AND METHODS}

All patients who underwent intramedullary nailing (with either K-nail or ILN) from 1st June 2004 to 1st June 2005 for Winquist type I and II femoral shaft fractures at the isthmus were retrospectively reviewed. Only cases with isolated femoral fractures and with follow up records of more than 6 months were included in the study. Patients with vascular injuries, compartment syndrome or polytrauma were excluded. Additional information was obtained by telephone interview and some patients returned to the clinic at our request for further evaluation as needed.

An independent reviewer from the Department of Radiology studied the radiographs. Radiological union was defined as the presence of bridging callus across the fracture site in 3 cortices $^{9}$. The fracture was considered healed when there was radiological union and the patient was able to weight-bear pain free ${ }^{9}$. Fractures taking longer than 6 months to unite were defined as delayed union whilst an absence of callus at the fracture site at 6 months was considered non-union. We also reviewed the type of open fracture as per Gustillo classification ${ }^{10}$. The degree of comminution of the fracture was graded according to Winquist classification, (Table I) ${ }^{11}$.

Post-operative fracture alignment was assessed using the Thoresen scoring system ${ }^{12}$, that includes parameters such as valgus/varus, procurvatum/ recurvatum, shortening and rotation (internal and external). The former two parameters were determined by examining the radiographs in both anteroposterior and lateral views. Rotation was determined clinically by the position of the patella relative to the anterior superior iliac spine and the presence of shortening was established by clinical measurement for limb-length discrepancy.

Statistical analyses included both the Chi-square and unpaired t-test, and was calculated using SPSS for Windows. 


\section{RESULTS}

During the study period, there were 107 cases of intramedullary nail fixation used on Winquist I and II femoral isthmus fractures. We were able to contact 93 patients - 43 cases using K-nail and 50 with ILN. The age range of patients in the study was 18 to 75 years, with a mean of 26.5 years for those who underwent K-nail procedure and 34.6 for ILN. There is no significant difference in between both groups in terms of sex, number of closed and open fractures and percentage of Winquist I vs. II fractures (Table III).

There was no difference in the union rate between both groups $(p=0.3282)$. In the ILN group, $94 \%$ of patients achieved union within six months and $95.3 \%$ of the K-nail group did so. There were 2 cases of non-union and none of delayed union in the K-nail group. The two non-union patients were treated with exchange nailing (both with ILN) and eventually proceeded to union. There was one case of non-union and 2 cases of delayed union in the ILN group. The patient with non-union was successfully treated with dynamization without bone grafting while the 2 with delayed union were bone grafted and dynamized, and both went on to achieve union. The ILN and K-nail groups did not differ significantly in their speed of radiological union $(p=0.1082)$ or fracture healing $(\mathrm{p}=0.3279)$. Although the fractures fixed with ILN united somewhat earlier as compared to those treated with K-nail, the difference was not statistically significant. There was no significant difference in postoperative fracture alignment between the 2 groups. Both groups had more than $90 \%$ of its scores in excellent range for each of the Thoresen parameters (Table IV).

One case in the K-nail group developed superficial wound infection, a condition that resolved after a course of antibiotics with no further evidence of deeper infection or osteomyelitis. There were 2 cases of implant migration and 2 cases of bent implant in the K-nail group. All 4 cases were subsequently treated with exchange nailing that led to fracture union. There were no cases of implant failure in the ILN group.

\section{DISCUSSION}

With the introduction of proximal and distal locking screws, intramedullary nailing has become the implant of choice for the treatment of virtually any femoral shaft fractures. The locking mechanism has enabled stabilization of even the most comminuted and unstable fractures that leads to more successful early rehabilitation. Most hospitals routinely use interlocking intramedullary nails to fix all types of femoral shaft fractures, including Winquist type I and II femoral isthmus fractures. The use of unlocked nailing has been virtually abandoned.

Unlocked intramedullary nails were initially developed for fixation of transverse and short oblique fractures around the midshaft region or the isthmus ${ }^{8}$. Nails of the same diameter as the narrowest part of medullary canal were usually used as they resist rotational displacement by friction. Interdigitation of the fracture ends provided further resistance against rotation ${ }^{8}$. Therefore, K-nails were usually reserved for Winquist I and II femoral shaft fractures around the isthmus. Indeed, the current study demonstrates that there is no significant difference in outcomes between ILN and K-nail fixation of patients in regards to rate of union, speed of union and femoral alignment. The percentage of delayed union and non-union encountered in the K-nail group of patients is also not significant.

Of concern is fact that the K-nail group had a higher rate of implant failures involving migration and bending. Surgeons should probably proceed more slowly in initiating weight bearing protocols when unlocked intramedullary nail fixation is employed. Inadvertent cracking of the fracture ends may be reduced and fixed with additional cerclage wire fixation.

On the other hand, one advantages of using the Küntscher nail is that the surgery is technically less demanding. Additionally, the K-nail procedure and does not require the use of an image intensifier (as the fracture is reduced via open method), so there is no unnecessary exposure to radiation and no radiographer is needed. The K-nail is also

Table I: Winquist classification for femoral shaft fractures ${ }^{11}$.

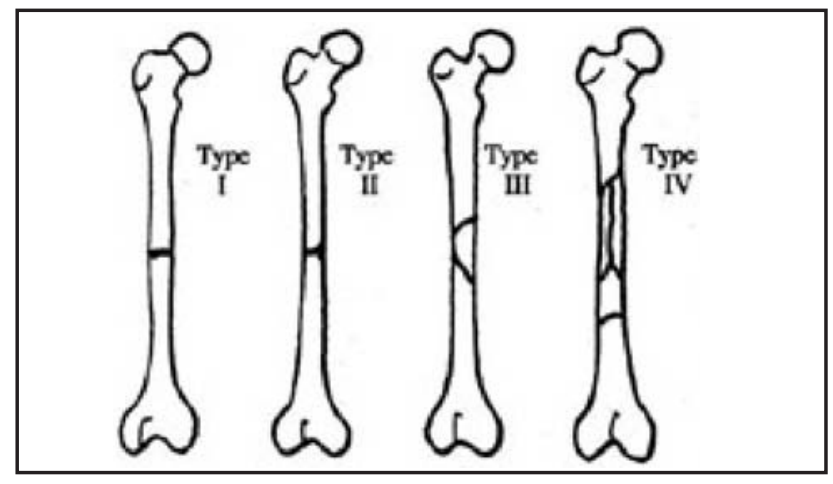

\begin{tabular}{|l|l|}
\hline Type & Description \\
\hline I & $\begin{array}{l}\text { Comminution is minimal or nonexistent at } \\
\text { fracture site } \\
\text { Comminution involves a fragment larger than in } \\
\text { type I but at least } 50 \% \text { of the circumference of } \\
\text { the cortices of two major fracture fragments are } \\
\text { intact } \\
\text { Between } 50 \text { and } 100 \% \text { of the circumference of } \\
\text { two major fracture fragments is comminuted } \\
\text { Cortical contact is lost; cortex is circumferentially } \\
\text { comminuted over a segment of bone }\end{array}$ \\
\hline
\end{tabular}


Table II: Thoresen scoring system ${ }^{12}$.

\begin{tabular}{|l|c|c|c|c|}
\hline Variable & Excellent & Good & Fair & Poor \\
\hline Malaligment & & 5 & 10 & $>10$ \\
$\quad$ Varus/Valgus & 5 & 10 & 15 & $>15$ \\
Procurvatum/recurvatum & 5 & 10 & 15 & $>15$ \\
Internal rotation & 5 & 15 & 20 & $>20$ \\
External rotation & 10 & 2 & 3 & $>3$ \\
Shortening(in cm) & 1 & 120 & 90 & $>15$ \\
Range of motion (knee) & $>120$ & 10 & 15 & Severe \\
Flexion & 5 & Sporadic, Minor & & \\
Extension deficit & None & &
\end{tabular}

Table III: Demographic and physical characteristics of study subjects.

\begin{tabular}{|l|c|c|c|}
\hline & ILN & K-nail & P value \\
\hline Number of fractures & 50 & 43 & \\
Mean Age & $34.6(13-84)$ & $26.5(14-72)$ & $\mathrm{P}=0.0328$ \\
Gender & 42 & 39 & $\mathrm{P}=0.3367$ \\
$\quad$ Male & 8 & 4 & $\mathrm{P}=0.6328$ \\
Female & 45 & 40 & \\
Closed Fractures & 4 & 3 & \\
Open Fracture Grade 1 \& & 1 & 0 & $\mathrm{P}=0.9633$ \\
Open Fracture Grade 3 & 37 & 32 & \\
Comminution & 13 & 11 & \\
$\quad$ Winquist type I & 13 & & \\
Winquist type II & & & \\
\hline
\end{tabular}

Table IV: Post-operative fracture alignment based on Thoresen's scoring system ${ }^{12}$.

\begin{tabular}{|c|c|c|c|}
\hline & ILN & K-nail & \\
\hline Valgus / Varus & & & \multirow{5}{*}{$\mathrm{p}=0.621$} \\
\hline Excellent & $46(92.0 \%)$ & $41(95.3 \%)$ & \\
\hline Good & 2 & 0 & \\
\hline Fair & 1 & 1 & \\
\hline Poor & 1 & 1 & \\
\hline Procurvatum/Recurvatum & & & \multirow{5}{*}{$p=0.5513$} \\
\hline Excellent & $49(98.0 \%)$ & $41(95.3 \%)$ & \\
\hline Good & 0 & 0 & \\
\hline Fair & 0 & 1 & \\
\hline Poor & 1 & 1 & \\
\hline Internal rotation & & & \multirow{5}{*}{$P=0.3047$} \\
\hline Excellent & $50(100 \%)$ & $41(95.3 \%)$ & \\
\hline Good & 0 & 0 & \\
\hline Fair & 0 & 1 & \\
\hline Poor & 0 & 1 & \\
\hline External rotation & & & \multirow{6}{*}{$p=0.3615$} \\
\hline Excellent & $49(98.0 \%)$ & $41(95.3 \%)$ & \\
\hline Good & 1 & 0 & \\
\hline Fair & 0 & 1 & \\
\hline Poor & 0 & 1 & \\
\hline Shortening & & & \\
\hline Excellent & $49(98.0 \%)$ & $43(100 \%)$ & \multirow{4}{*}{$p=0.3511$} \\
\hline Good & 1 & 0 & \\
\hline Fair & 0 & 0 & \\
\hline Poor & 0 & 0 & \\
\hline
\end{tabular}


much less expensive as compared to standard ILN, an important factor in countries with limited financial resources. Therefore, for economic and technical reasons, use of the Küntscher nail is still a viable option.

The limitation of this study is the small sample size and limited case study material available for analysis. It is also important to note that the delineation of the two groups may have been biased since the type of implant used depends on surgeon's preference in addition to the clinical and radiographic presentation of the fracture.

\section{CONCLUSION}

Unlocked intramedullary nailing can provide comparable rate of union with interlocking intramedullary nailing when used for fixation of non-comminuted femur fractures at the isthmus. There is however a higher incidence of implant migration and bending associated with the use of unlocked nailing. Considering the cost and surgical aspects of this treatment option, unlocked nailing is still a viable option for selected femoral fractures in many hospitals, especially those with limited financial resources or less technical expertise.

\section{Conflict of interest statement}

We disclose that there is no financial and personal relationships with other people, or organisations, that could inappropriately influence (bias) our work, all within 3 years of the beginning this work. There are no conflicts of interest. 


\section{REFERENCES}

1. Kempf I, Grosse A, Lafforgued L: L'enclouage avec blocage de la rotation on "clou blogue" principles, technique, indications et premiers resultants, Communication a la journee d'hiver, Sofcot, 1976.

2. Thorensen BO, Alho A, Ekel A. Interlocking intramedullary nailing in femoral shaft fractures: a report of forty-eight cases. $J$ Bone Joint Surg. 1985; 67A: 1313.

3. White GM, Healy WL, Brumbeck RJ. The treatment of fractures of the femoral shaft with the Brooker-Willis distal locking intramedullary nail. J Bone Joint Surg. 1986; 68A: 865.

4. Taylor JC: Treatment of distal femoral fractures with the Russell-Taylor nail. Tech Orthop. 1994; 9: 225.

5. Canale, ST,editor. Fractures of the Lower Extermity. In: edited by S. Terry Canale. Campbell's Operative Orthopaedics. 10th edition: Mosby; 2003: 2725-872.

6. Rüedi TP, Lüscher JN. Results after internal fixation of comminuted fractures of the femoral shaft with DC plates. Clin Orthop. 1979; $138: 74$.

7. Winquist RA, Hansen ST Jr. Comminuted fractures of the femoral shaft treated by intramedullary nailing. Orthop Clin North Am. 1989; 11: 633 .

8. Schatzker J. Fractures of the Femur. In: Schatzker J, Tile M. The Rationale of Operative Fracture Care, 3rd Edition. Springer; 1996. 367-85.

9. Ricci WM, Bellabarba C, Evanoff B, Herscovici D, DiPasquale T, Sanders R. Retrograde versus Antegrade Nailing of Femoral Shaft Fractures. J Ortho Trauma. 2001; 15(3): 161-9.

10. Gustilo RB, Mendoza RM, Williams DN. Problems in the management of type III (severe) open fractures: a new classification of Type III open fractures. J Trauma. 1984; 24: 742-6.

11. Winquist RA, Hansen ST, Clawson DK. Closed intramedullary nailing of femoral fractures. J Bone Joint Surg. 1984; 66(A): 52939.

12. Thoresen BO, Alho EA, Stromsoe K, Folleras G, Haukebo A. Interlocking intramedullary nailing in femoral shaft fractures. A report of 48 cases. J Bone Joint Surg. 1985; 167(A): 1313-20. 